\title{
Desenvolvimento de dispositivo e estudo do comportamento ao microdesgaste abrasivo do aço AISI 420 temperado e revenido
}

\author{
Apparatus development and study of abrasive \\ microwear behaviour of quenched and \\ tempered AISI 420 steel
}

\author{
Waldenir Caravantes Santos ${ }^{1}$, Joaquim Olimpio Pereira Neto ${ }^{1}$ \\ Raphael Oliveira da Silva ${ }^{1}$, Gledison Rodriguês ${ }^{1}$ \\ Jeferson Aparecido Moreto², Marcos Dorigão Manfrinato ${ }^{1}$ \\ Luciana Sgarbi Rossino ${ }^{1,3}$
}

\footnotetext{
${ }^{1}$ Faculdade de Tecnologia José Crespo Gonzales - FATEC-Sorocaba - CEP: 18013-280, Sorocaba, SP

e-mail: waldenir_c@hotmail.com; joaquimopneto@hotmail.com; raphael1221@live.com,r.gledison@gmail.com

${ }^{2}$ Instituto Federal Goiano - IF Goiano - CEP: 75901-970, Rio Verde, Go

e-mail: jeferson_moreto@yahoo.com.br

${ }^{3}$ Universidade Federal de São Carlos - UFSCAR Campus Sorocaba - CEP: 18.052-780, Sorocaba, SP

e-mail: lu-sgarbi@hotmail.com
}

\section{RESUMO}

O ensaio de micro desgaste abrasivo tem sido objeto de uma quantidade significativa de pesquisas nos últimos anos, quando o seu potencial para avaliar o comportamento de recobrimentos finos se tornou relevante. O objetivo deste trabalho é a construção de um dispositivo para a realização de ensaios de micro desgaste abrasivo por esfera fixa. O contato abrasivo é realizado por uma esfera de aço AISI 52100, a qual é presa num eixo que gira com grande precisão, com ajuda de um motor, em relação a uma amostra plana que se manterá estacionária. A carga normal de ensaio é aplicada através de ajustes de peso no suporte pivotado do corpo de prova, a qual pode ser variada a cada ensaio realizado. Este dispositivo foi utilizado para a determinação da resistência ao desgaste abrasivo e da eficácia de tratamentos de superfície utilizados em peças que sofrem este tipo de solicitação em serviço, além de utilizá-lo para estudar novos produtos desenvolvidos para o aumento de resistência ao desgaste de superfícies. Foi avaliada a resistência ao microdesgaste abrasivo de aço AISI 420 temperado e revenido. Observou-se que o aumento da dureza do material tratado aumentou a resistência ao desgaste abrasivo quando comparado com o material sem tratamento térmico.

Palavras-chave: desgaste microabrasivo, esfera fixa, aço AISI 420, configuração experimental.

\begin{abstract}
The abrasive microwear testing has been the subject of a significant amount of research in recent years, when its potential to evaluate the behaviour of thin coating became relevant. The aim of this work is to build a apparatus for abrasive microwear testing by rotating sphere. The abrasive contact is performed by a AISI 52100 steel ball which rotates, with great accuracy with the help of an electric motor, in relation to a flat sample that will remain stationary. The normal load is applied by weight adjustments in the support of the test specimen, which can be varied for each performed test. This device was used to determine the abrasive wear resistance and effectiveness of surface treatments used in parts that undergo this kind of requirement in service, and also for studying new products developed for increasing the wear resistance of surfaces. The microwear resistance of the quenched and tempered AISI 420 steel was evaluated. It was observed that increasing the hardness of the treated material produced an increased wear resistance when compared with untreated material
\end{abstract}

Keywords: microabrasive wear, rotating sphere, stainless steel AISI 420, experimental setup.

1. INTRODUÇÃO

A palavra tribologia, derivada do grego, significa estudo do atrito, sendo a ciência e tecnologia que estuda a 
interação entre superfícies em movimento relativo e as práticas relacionadas a este fenômeno e, para isso utiliza princípios como atrito, desgaste e lubrificação [1]].

Desgaste é a perda progressiva de matéria da superfície de um corpo sólido devido ao contato e movimento relativo com um outro corpo sólido, líquido ou gasoso, sendo um fenômeno complexo que depende das condições de deslizamento e propriedades dos materiais [ㄹ, $\underline{3}$ ]. Esta perda de material pode acarretar diminuição da funcionalidade do componente e consequentemente de equipamentos no qual está inserido. Como o fenômeno do desgaste é comum na grande maioria dos equipamentos mecânicos, a sua ocorrência pode ser o fator determinante na quantificação da vida útil de tais dispositivos [4].

Assim, o estudo dos mecanismos de desgaste e da resistência ao desgaste em um sistema tribológico é fundamental para a otimização na escolha dos materiais envolvidos e para a previsão da durabilidade do sistema. Este tipo de estudo é, normalmente, feito através de ensaios em equipamentos que simulam as condições tribológicas existentes no funcionamento do sistema, na aplicação real. Desta forma, os equipamentos que se destinam à simulação de sistemas tribológicos devem ser específicos para o tipo ou o mecanismo de desgaste que se pretende estudar [ $\underline{3}, \underline{4}]$.

Vários mecanismos de desgaste podem ser observados em situações práticas, e os mais importantes são: abrasão, adesão, fadiga e corrosão [ $[\underline{5}, \underline{6}, \underline{7}]$. O desgaste por abrasão ocorre entre superfícies de durezas diferentes, causado por partículas ou protuberâncias duras presentes entre as superfícies em contato sob movimento relativo ou por micro-irregularidades de tais superfícies. Já o desgaste por adesão, ocorre quando as forças atômicas de atração que surgem entre as superfícies dos materiais sob carregamento relativo são mais fortes que as propriedades inerentes de qualquer das superfícies, com subsequente quebra de ligação adesiva entre as superfícies em contato criando partículas de desgaste. Para o desgaste por fadiga, tensões e deformações cisalhantes cíclicas na região superficiais e sub-superficiais no material formam trincas que resultam na separação de material. A corrosão é um mecanismo indireto de desgaste, em que o produto de reações químicas como um resultado de interação química entre os elementos de um tribosistema iniciado pela ação tecnológica gera detritos que atuam como desgaste abrasivo de três corpos [ $[\underline{5}, \underline{6}, \underline{7}]$.

A resistência ao desgaste abrasivo de um material pode ser medida por uma grande quantidade de ensaios de laboratório e o valor obtido depende não somente das propriedades intrínsecas do material como também do método de ensaio empregado [3] .

Neste contexto, em que se procuram ensaios de laboratório, cujos resultados possam ser transferidos para situações mais próximas das reais, tem-se o ensaio de microabrasão. O ensaio de microabrasão tem sido objeto de uma quantidade significativa de pesquisas nos últimos anos, quando o seu potencial para se avaliar o comportamento de recobrimentos finos e materiais volumétricos de um modo sensível se tornou aparente. Ele é predominantemente usado como um ensaio de abrasão em microescala aonde as partículas abrasivas são menores do que cerca de $10 \mu \mathrm{m}$. Uma vez que o volume de desgaste ou profundidade gerada pelas partículas finas é muito pequeno, o ensaio de microabrasão é adequado para se medir a resistência ao desgaste de recobrimentos finos ou outras camadas produzidas pela engenharia de superfície [8]. Além disso, este ensaio também tem sido usado para se avaliar a resistência ao desgaste abrasivo de materiais volumétricos como aços ferramenta, aços carbono, vidros, cerâmicas, polímeros, ferros fundidos brancos alto cromo e até mesmo compósitos de restauração dentária [8, 9$]$.

O ensaio de micro desgaste abrasivo consiste em promover o contato entre uma esfera e uma amostra plana, com ou sem a presença de abrasivo, com a esfera girando em relação à amostra. O resultado desse contato é uma região desgastada em forma de calota esférica, que mantém relações geométricas com a esfera que a gerou. Assim, ao medir o diâmetro da calota pode-se relacioná-lo com a quantidade de material removido da amostra [1].

Pode-se verificar a existência de muitos dispositivos de micro desgaste por abrasão disponíveis nos principais centros de pesquisa do país $[\underline{10}, \underline{11}, \underline{12}, \underline{13}, \underline{14}, \underline{15}, \underline{16}]$.

O objetivo deste trabalho é o desenvolvimento de um dispositivo para realização de ensaios de micro desgaste abrasivo por esfera fixa, o qual será utilizado para determinação do comportamento, resistência e eficiência de tratamentos de superfície no aumento da resistência ao desgaste de materiais sujeitos a este fenômeno em serviço. Determinou-se, com o desenvolvimento deste trabalho, a resistência ao desgaste microabrasivo de aço AISI 420 temperado e revenido.

\section{DESENVOLVIMENTO}

\subsection{Dispositivo de Desgaste}


Dois tipos diferentes de ensaio de micro desgaste podem ser realizados em laboratório, conforme ilustra o esquema na Figura 1. A configuração de esfera fixa (Figura 1(a)) é utilizada para promover cargas elevadas de contato e consequentemente altas tensões no ensaio. A configuração com a esfera livre ilustrada na Figura 1(b) promove pequenas cargas de ensaio. Por possibilitar uma variedade abrangente de ajuste, o ensaio do tipo esfera fixa tem sido amplamente utilizado para estudo de micro desgaste em uma variedade de materiais.

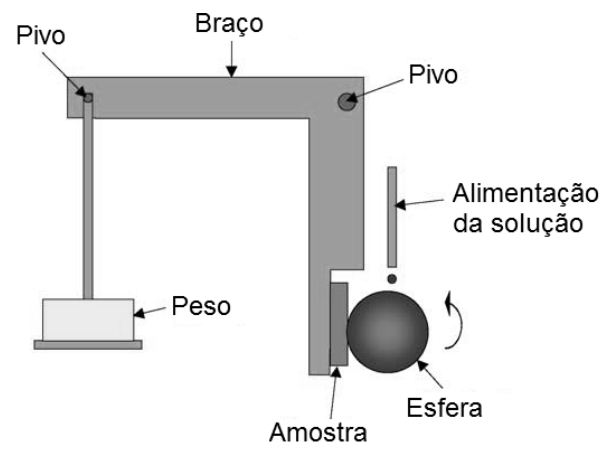

(a)

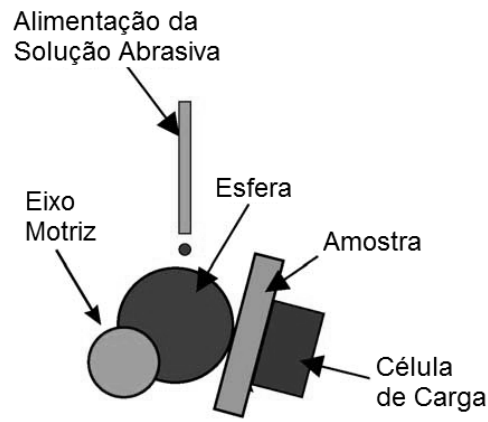

(b)

Figura 1: Principais tipos de micro desgaste por (a) esfera fixa e (b) esfera livre [프].

Assim, neste trabalho foi desenvolvido um dispositivo para ensaio de micro desgaste por esfera fixa de baixo custo e fácil utilização. Este ensaio consiste em promover o contato entre uma esfera e uma amostra plana, com a esfera girando com grande precisão em relação à amostra que se mantém estacionária, possibilitando obter cargas elevadas e consequentemente altas tensões no ensaio. A esfera é mantida em contato sobre pressão com corpo de prova, e a carga normal de ensaio é aplicada através de ajustes de peso em um suporte, a qual pode ser variada a cada ensaio realizado. Um contra peso é utilizado para equilíbrio da amostra. O contato é realizado por uma esfera de aço AISI 52100 de 1 polegada de diâmetro. A velocidade de rotação da esfera, promovida por um motor, é ajustada com precisão e mantida constante durante toda a realização do ensaio.

O resultado do contato estudado neste trabalho é uma região desgastada em forma de calota esférica, possuindo relações geométricas com a esfera que a gerou. Assim, conhecendo-se o diâmetro da calota podese determinar a quantidade de material removido durante o ensaio. A Figura 2 ilustra a formação da calota no ensaio de micro desgaste [18].

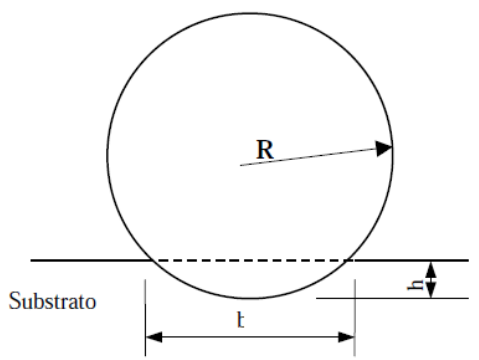

Figura 2: Diagrama esquemático que ilustra a geometria da calota formada pelo ensaio de micro desgaste.

Para uma calota de desgaste com geometria esférica produzida por uma esfera de raio “R” em uma amostra plana, o volume desgastado pode ser calculado de acordo com a equação (1) em que R é o raio da esfera, b é o diâmetro médio da calota e $\mathrm{V}$ é o volume de desgaste [18]. Através deste cálculo, determina-se a resistência ao desgaste dos materiais em que, quanto maior o volume desgastado e, consequentemente, maior a calota formada, menos resistente ao desgaste deve ser o material analisado. Pode-se também determinar o coeficiente de desgaste específico $\left(\mathrm{K}_{\mathrm{S}}\right)$, o qual pode ser interpretado como o volume de material desgastado em função da distância percorrida (S) e da carga aplicada (N) de acordo com a equação (2) [18]. Este parâmetro mede a severidade do desgaste em que, quanto maior for $\mathrm{K}_{\mathrm{S}}$, maior será a taxa de desgaste. 


$$
\begin{array}{ll}
V=\pi \frac{\mathrm{b}^{4}}{64 \mathrm{R}^{2}}\left(\mathrm{R}-\frac{\mathrm{b}^{2}}{\mathrm{gR}}\right) \approx \frac{\pi \mathrm{b}^{4}}{64 \mathrm{R}} & \text { para } \mathrm{b}<<<R \\
K_{S}=\frac{1}{N . S} \frac{\pi b^{4}}{64 R} & \text { para } b<<R
\end{array}
$$

\subsection{Ensaio de Desgaste em Aço AISI 420 Temperado e Revenido}

Para o desenvolvimento deste trabalho, foi utilizado o aço inoxidável ABNT/AISI 420 fornecido na forma de barra redonda no estado recozido com dureza máxima de 200 HB. A composição nominal do material estudado está apresentada na Tabela 1, determinada em Espectrômetro de Emissão Optica, Marca SPECTROMAXX, alocado no Laboratório de Materiais da Fatec/Sorocaba.

Tabela 1: Composição química, wt\%, da liga AISI 420 [19]

\begin{tabular}{c|c|c|c|c|c|c}
\hline ABNT/AISI 420 & C min & Mn max & P max & S max & Si max & Cr \\
\hline Nominal & 0,15 & 1,00 & 0,04 & 0,03 & 1,00 & $12-14$ \\
\hline Obtido & 0,371 & 0,344 & 0,018 & 0,027 & 0,369 & 12,18 \\
\hline
\end{tabular}

Para a realização dos ensaios de micro desgaste abrasivo por esfera rotativa, os corpos de prova foram fabricados nas dimensões definidas na Figura 3. Estas dimensões foram determinadas de maneira a que o corpo de prova fosse adequadamente encaixado no suporte do dispositivo desenvolvido neste trabalho.

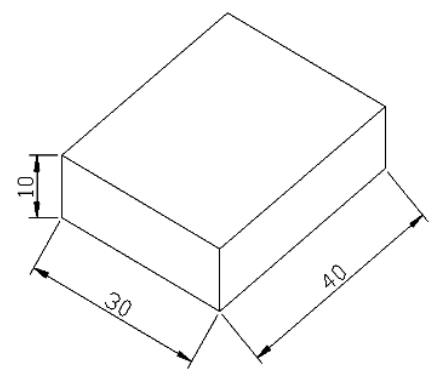

Figura 3: Geometria e dimensional, em milimetros, do corpo de prova para o ensaio de desgaste.

Por definição, aço inox são ligas de ferro contendo pelo menos $10 \%$ de cromo, podendo conter também outros elementos de liga, o que confere a esta liga alta resistência à corrosão e oxidação [20]. A resistência à corrosão e oxidação destas ligas está associada ao fenômeno de passivação, isto é, à formação de uma camada de óxidos mistos, que é impermeável e insolúvel nos meios corrosivos usuais. As principais famílias de aços inoxidáveis são: ferríticos, austeníticos, martensíticos, endurecíeis por precipitação e duplex (austenitico/ferritico). Os aços inoxidáveis martensíticos, do qual faz parte o aço ABNT/AISI 420, podem ser considerados equivalentes aos aços para têmpera e revenidos com a diferença no teor de cromo, possuindo elevadíssima temperabilidade e aumento da resistência ao amolecimento no revenimento. Além disso, pode ocorrer endurecimento secundário pela precipitação de carbonetos de cromo [21].

A temperatura de austenitização dos aços inoxidáveis ABNT/AISI 420 deve ser aplicada entre 980 e $1040^{\circ} \mathrm{C}$, com têmpera em ar ou óleo. O revenimento deve ser realizado a uma faixa de 210 a $370^{\circ} \mathrm{C}$, obtendose uma dureza entre 48 a 65 HRC [22]. Revenimentos entre 450 e $500^{\circ} \mathrm{C}$ pode resultar em perda da tenacidade, e acima de $500^{\circ} \mathrm{C}$ há uma rápida redução na dureza e na resistência mecânica, acompanhado por aumento de ductilidade e tenacidade [21]

Os aços inoxidáveis martensíticos tipo 420, devido à sua alta dureza e razoável tenacidade que adquirem após adequado tratamento térmico, são utilizados principalmente nos casos em que é necessária dureza, força e resistência ao desgaste, sendo empregados em cutelaria, instrumentos cirúrgicos, eixos de bomba, válvulas, peças de motores a jato, mancais de esferas, parafusos, buchas, etc [23] .

Para determinar a resistência ao desgaste do aço inoxidável martensítico ABNT/AISI 420, uma serie de tratamento térmico foi realizado. As amostras foram tratadas termicamentes em fornos tipo mufla, as quais 
foram austenitizadas a $980^{\circ} \mathrm{C}$ (T980) e $1050^{\circ} \mathrm{C}$ (T1050) e temperadas em óleo, com posterior revenimento, por 25 minutos, a diferentes temperaturas.

Todos os materiais tiveram suas durezas medidas utilizando-se um Durômetro Rockwell Harolness Testing Machine Mitutoyo HR 300, na escala HRC, alocado no Laboratório de Ensaios Mecânicos da Fatec/Sorocaba.

Para determinar a resistência ao desgaste do material estudado, duas séries de ensaio foram realizadas. No primeiro caso, para determinar a influência dos tratamentos do tratamento térmico na resistência ao desgaste do material, realizou-se ensaios de micro desgaste abrasivo por esfera rotativa fixa no materiais sem tratamento e no material revenido a diferentes temperaturas após tempera e austenitização a $980^{\circ} \mathrm{C}$ e $1050^{\circ} \mathrm{C}$. A rotação da esfera de ensaio foi de 1493 RPM com carga de 16,7 N, a um tempo de ensaio de 10 minutos.

Para verificar a influência do tempo de ensaio na resistência ao desgaste do material estudado, foram realizados ensaios a 10 e 15 minutos para o material austenitizado a $980^{\circ} \mathrm{C}$ e temperado (T980), austenitizado a $1050^{\circ} \mathrm{C}$ e temperado (T1050), tempearado após austenitização a $980^{\circ} \mathrm{C}$ com revenimento a $420^{\circ} \mathrm{C}$ (T980R420) e temperado após austenitização a $1050^{\circ} \mathrm{C}$ com revenimento a $580^{\circ} \mathrm{C}$ (T1050R580). A rotação da esfera de ensaio foi de 1493 RPM com carga de $16,7 \mathrm{~N}$.

Todos os ensaios de microdesgaste abrasivo foram realizados utilizando abrasivo de alumina (líquido abrasivo a base de alumina de $1 \mu \mathrm{m}$ com concentração de $200 \mathrm{~g} / \mathrm{L}$ ) aplicado a cada $10 \mathrm{~s}$.

Para medir a calota impressa foi usado um estereoscópico da marca OLYMPUS modelo SZ61, com câmera de 6 megapixels e software Análise 2.0.

\section{RESULTADOS E DISCUSSÕES}

\subsection{Dispositivo de Desgaste}

A Figura 4 ilustra um esquema do dispositivo. O dispositivo foi confeccionado em material SAE 1020, material de baixo custo que atende a rigidez solicitada pelo dispositivo, com tratamento superficial zincado amarelo para evitar oxidação das peças. Para o desenvolvimento do dispositivo, primeiramente foram analisados dispositivos já existentes na literatura. Assim pode-se dimensionar as peças que iriam compor o dispositivo de forma mais eficaz. No desenvolvimento do dispositivo foi levado em consideração a segurança e o controle de velocidade. Para segurança foi disposto uma proteção do sobre o acoplamento do motor ao eixo de giro da esfera. O dispositivo desenvolvido pode ser observado na Figura 5.

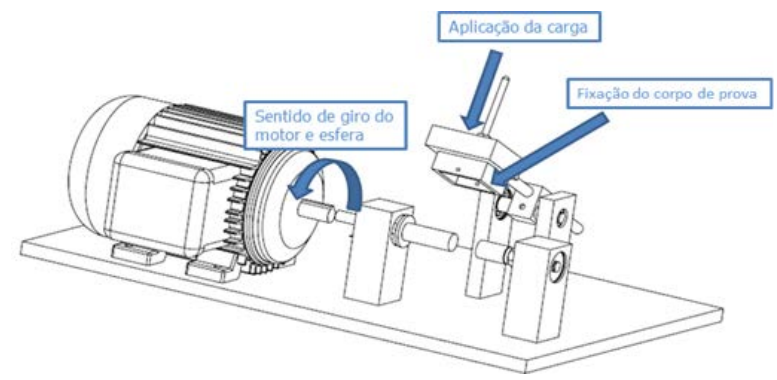

Figura 4: Esquema do dispositivo de desgaste desenvolvido neste trabalho, por esfera fixa horizontal.

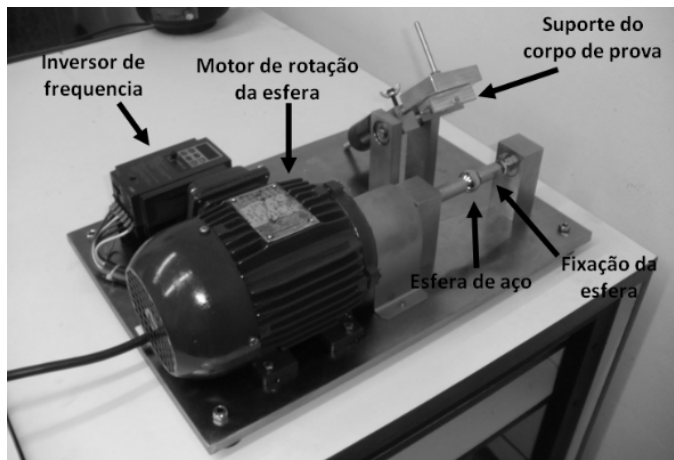

Figura 5: Vista frontal do dispositivo de microdesgaste esfera fixa. 
Foi usado motor elétrico trifásico de $0.75 \mathrm{cv}$. Para controle da velocidade de rotação da esfera, foi utilizado inversor WEG CF08, com regulagem de velocidade pelo potenciômetro do próprio inversor sendo indicado no visor em Hertz. Para conversão da unidade de Hertz para RPM, pode-se utilizar a Tabela 3, uma vez que a distância percorrida pela esfera com relação ao corpo de prova corresponde à multiplicação entre o tante no cálculo do coeficiente de desgaste.

Tabela 3: Tabela conversão de Hertz para RPM do motortempo de ensaio (minutos), velocidade de rotação (RPM) e perímetro da esfera (m), esta conversão é impor

\begin{tabular}{l|l|l|l|l|l|l|l|l|l|l|l|l|l}
\hline $\mathrm{Hz}$ & 1 & 5 & 10 & 15 & 20 & 25 & 30 & 35 & 40 & 45 & 50 & 55 & 60 \\
\hline $\mathrm{RPM}$ & 30 & 147 & 296 & 447 & 596 & 744 & 894 & 1042 & 1193 & 1344 & 1493 & 1642 & 1792 \\
\hline
\end{tabular}

A fixação da esfera é feita por pressão de dois eixos que estão fixados nos mancais frontais, conforme ilustra a Figura 6(a), os quais possuem rolamentos de dupla carreira de esfera fixa a fim de permitir maior precisão de alinhamento da esfera de desgaste e garantir que o eixo suporte as cargas axiais e tangenciais as quais esta peça possa ser submetida em serviço, além de garantir que a esfera não solte durante a realização do ensaio. Em paralelo ao rolamento de dupla carreira, foi colocado rolamento simples para eliminar batimento e maior alinhamento dos eixos. Os defletores têm a função de proteger e garantir o bom funcionamento do rolamento contra a entrada de detritos no sistema.

A esfera é fixada pelos eixos com sua face côncava no raio de $12,7 \mathrm{~mm}$, sendo um fixo e outro com rosca interna esquerda M10 x 1,5 para facilitar a substituição da esfera, conforme ilustra a Figura 6(a), uma vez que para cada ensaio é utilizado uma esfera nova.

Nos mancais traseiros, conforme ilustra a Figura 6(b), foram utilizados rolamentos fixo de esfera dupla, para menor atrito no eixo de fixação da carga de contato e do corpo de prova, garantindo alinhamento e perpendicularidade entre a esfera e o corpo de prova.

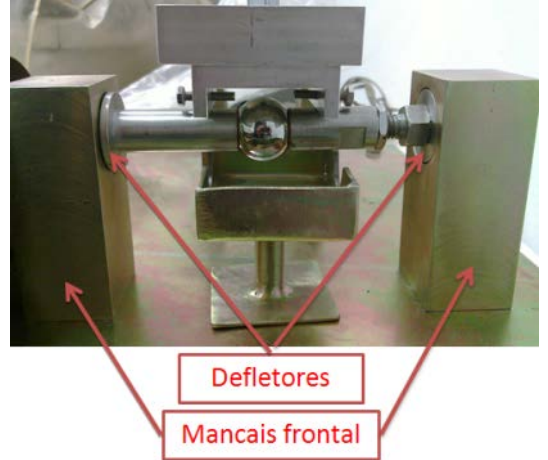

(a)

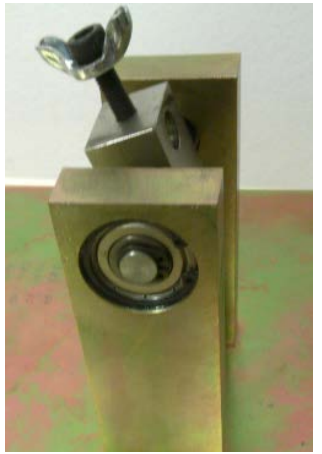

(b)

Figura 6: (a) mancais frontais, eixo e esfera de desgaste, (b) mancais traseiros.

A Figura 7 ilustra o suporte de fixação da carga de contato e do corpo de prova, construído em alumínio para aliviar o peso, fixando o corpo de prova com parafuso sextavado nas laterais. A carga é posicionada em um eixo ao centro da caixa de acomodação do corpo de prova, o qual é fixado por rosca, permitindo que o suporte do corpo de prova seja posicionado adequadamente à esfera de contato. Assim, pode-se utilizar o mesmo corpo de prova em diversos ensaios, mudando somente o posicionamento deste com a esfera de contato de um ensaio para o outro, garantindo a aplicação da carga na posição central da esfera.

Este sistema foi feito em forma de balancim para que haja apenas a carga posicionada no eixo do suporte da carga de contato, a fim de garantir que a carga aplicada no corpo de prova não variasse com a massa do corpo de prova e do sistema de aplicação da carga. Este contra peso pode ser regulado facilmente, afastando ou aproximando-o do corpo de prova com precisão, a fim de deixar o sistema em equilíbrio, conforme ilustra a Figura 7. Para sabermos se o sistema está em equilíbrio, foi colocado um multímetro medindo a continuidade de corrente, quando o corpo de prova fica em equilíbrio temos a continuidade aberta, podendo ser ouvido por um apito sonoro emitido pelo multímetro. 


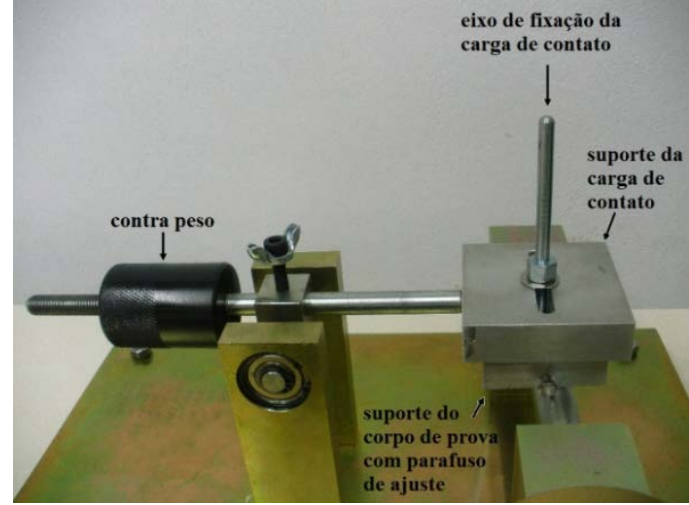

(a)

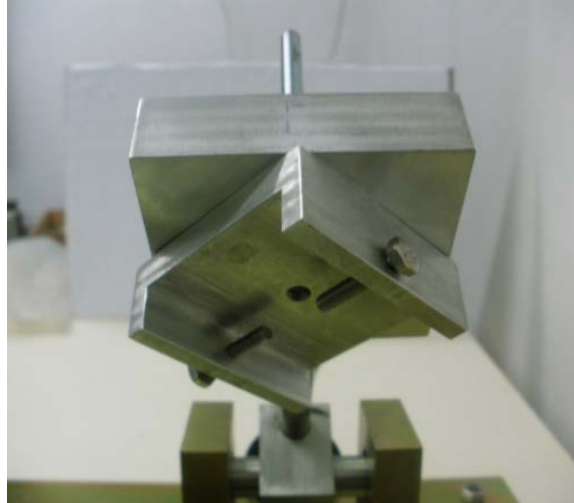

(b)

Figura 7: (a) sistema de aplicação da carga de contato, (b) suporte do corpo de prova.

\subsection{Ensaio de Dureza do Aço AISI 420 Temperado e Revenido}

A Figura 8 apresenta os resultados das durezas e para os materiais tratados termicamente. O material sem tratamento apresentou dureza de $91 \mathrm{HRB}$ enquanto os materiais temperados após austenitização a $980^{\circ} \mathrm{C}$ (T980) e $1050^{\circ} \mathrm{C}(\mathrm{T} 1050)$ apresentaram, respectivamente, dureza de 50 HRC e 55 HRC. De forma geral, o tratamento térmico de têmpera aumenta consideravelmente a dureza do material, a qual é diminuida com o tratamento de revenimento.

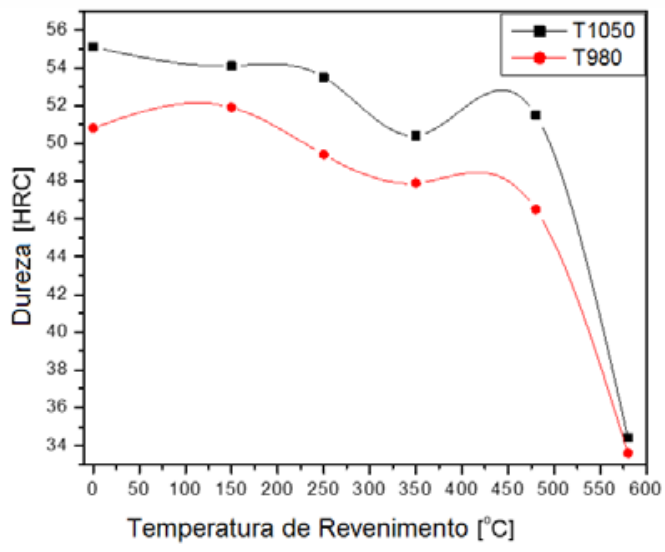

Figura 8: Gráfico de variação da dureza com relação a temperatura de revenimento para aço AISI 420 austenitizados a $980^{\circ} \mathrm{C}(\mathrm{T} 980)$ e $1050^{\circ} \mathrm{C}(\mathrm{T} 1050)$.

Porém, observa-se um aumento de dureza do material T1050 com relação ao material T980. Isto ocorre porque, a partir da temperatura de austenitização de $900^{\circ} \mathrm{C}$ há um aumento da dureza devido a dissolução de carbonetos de cromo na austenita, aumentando o grau de supersaturação da martensita. A dureza vai atingir seu pico máximo exatamente em $1050^{\circ} \mathrm{C}$, acima da qual acontece uma diminuição considerável da dureza devido ao aumento considerável da fração de austenita retida e possível crescimento de grão. Estes resultados corroboram com aqueles obtidos por PINEDO [24] e por ISFAHANY et al. [25] .

Observa-se, analisando a Figura 8, um ligeiro aumento da dureza do material na tempertura de revenimento superior a $420^{\circ} \mathrm{C}$. Este comportamento pode ser explicado devido ao endurecimento secundário que ocorre na temperatura de $420^{\circ} \mathrm{C}$, com posterior amolecimento do material a $580^{\circ} \mathrm{C}$. As maiores faixas de temperatura de revenimento são frequentemente empregada para obtenção da melhor combinação de propriedades para fins estruturais, porém deve-se tomar cuidado com o emprego de temperaturas muito altas para evitar a reaustenitização parcial do material, o que conduziria à presença de martensita não revenida no resfriamento, sendo necessário o emprego de duplo revenido para promover a formação da martensita revenida a partir da martensita não revenida [21]. 
Conforme definido por PINEDO [24], o endurecimento secundário é causado pela precipitação de carbonetos do tipo $\mathrm{M}_{3} \mathrm{C}$. Já a diminuição na dureza com o aumento na temperatura de revenimento está associado com a transformação do carboneto $\mathrm{M}_{7} \mathrm{C}_{3}$ em $\mathrm{M}_{23} \mathrm{C}_{6}$, seguida de seu coalescimento [24, 25].

\subsection{Ensaio de Desgaste no Aço AISI 420 Temperado e Revenido}

Na Tabela 4 são apresentados os diâmetros das calotas de desgaste obtidas após a realização dos ensaios de mcirodesgaste abrasivo a 10 minutos e 15 minutos para verificar o efeito do tempo de ensaio na resistência ao desgaste do material estudado. A partir dos dados apresentados na Tabela 5 e utilizando a equação (1), determinou-se o volume de desgaste, conforme mostra a Figura 9, para os materiais temperados (T980 e T1050), tempeardos após austenitização a $980^{\circ}$ e posterior revenimento a $420^{\circ} \mathrm{C}$ (T980R420) e temperados após austenitização a $1050^{\circ} \mathrm{C}$ com revenimento a $580^{\circ} \mathrm{C}(\mathrm{T} 1050 \mathrm{R} 580)$.

Tabela 4: Diâmetro das calotas de desgaste obtidas nos tempos de ensaio de microdesgaste abrasivo de 10 e 15 minutos

\begin{tabular}{c|c|c}
\hline & Diâmetro da Calota 10 $\mathbf{~ i n}(\mathbf{m m})$ & Diâmetro da Calota 15 min (mm) \\
\hline MB & 9,95 & 11,53 \\
\hline T980 & 4,90 & 6,22 \\
\hline T980R420 & 4,82 & 5,12 \\
\hline T1050 & 4,67 & 5,03 \\
\hline T1050R580 & 5,76 & 6,23 \\
\hline
\end{tabular}

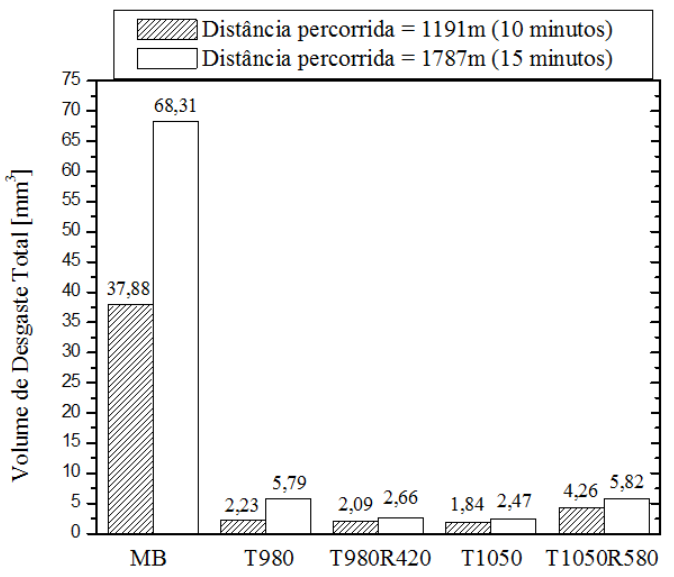

Figura 9: Volume total de desgaste $\left(\mathrm{mm}^{3}\right)$ para 10 minutos e 15 minutos de ensaio.

Observa-se que, quanto maior o tempo de ensaio, maior é o volume de desgaste apresentado pelos materiais estudados, independente do tratamento realizado no material.

Também observa-se, através da Figura 9, que o material base (MB) apresentou a menor resistência ao desgaste dentro todos os materiais estudados, devido a este estar no estado recozido com dureza menor (91 HRB). A resistência ao desgaste do aço ABNT/AISI 420 tratado termicamente aumentou consideravelmente com relação ao material base, mostrando que o tratamento térmico realizado foi eficiente no aumento da dureza e, por consequencia, no aumento da resistência ao desgaste do material.

Pode-se verificar, analisando a Figura 9, que o material T1050, material de maior dureza dentre todos estudados (55HRC), apresentou a maior resistência ao desgaste se comparado a todos os materiais estudados. Porém, apesar da dureza do material T1050 ter sido superior ao do material T980R420 (49 HRC), a resistância ao desgaste destes dois materiais foram muito próximas.

Também, apesar da dureza do material T980 (50 HRC) ter sido semelhante a dureza do material T980R420, a resistência ao desgaste deste ultimo foi ligeiramente maior. Isto demostra que não só a dureza influencia na resistência ao desgaste mas também deve-se levar em conta a microestrutura do material analisado. Talvez a maior resistência ao desgaste apresentada pelo material T980R420 esteja relacionada com a formação dos carbonetos formados pelo tratamento térmico de têmpera e revenimento. 
Deve-se levar em conta que a adição de elementos de liga nos aços conduzem a uma maior estabilidade térmica e resistência ao desgaste destes materiais em serviço. A presença destes elementos de liga nos aços conduzem a formação de carbonetos, tais como $M_{3} C, M_{23} C_{6}, M_{6} C$ e $M_{7} C_{3}$, os quais possuem alta dureza aumentando a resistência ao desgaste dos aços na proporção de volume de carbonetos e dureza destes [26]. Assim, ao determinar a resistência ao desgaste dos materiais, deve-se levar em conta a presença dos carbonetos na microestrutura do material.

A Figura 10 ilustra o coeficiente de desgaste $K_{s}$ em função da dureza dos materiais estudados, para os tempos de ensaio de 10 minutos (distância percorrida de 1191m) e 15 minutos (distância percorrida de $1787 \mathrm{~m})$.

O coeficiente de desgaste dos materiais tratados se apresentaram muito inferiores ao do material base, que corresponde aos pontos de maior dureza da Figura 10. Observa-se que o coeficiente de desgaste do material base após 15 minutos de ensaio é superior ao coeficiente de desgaste do material base após 10 minutos de ensaio, evidenciando a severidade do desgaste com o aumento da distância percorrida. Já para os materiais tratados, apesar do ligeiro aumento do coeficiente de desgaste para os materiais ensaiados a 15 minutos, os valores apresentaram-se similares ao comportamento dos materiais ensaiados a 10 minutos. Provavelmente este fato esteja relacionado com o aumento na eficiência da resistência ao desgaste com o tratamento térmico, que mantem maiores resistência ao desgaste dos materiais tratados mesmo em condições mais severas de ensaio.

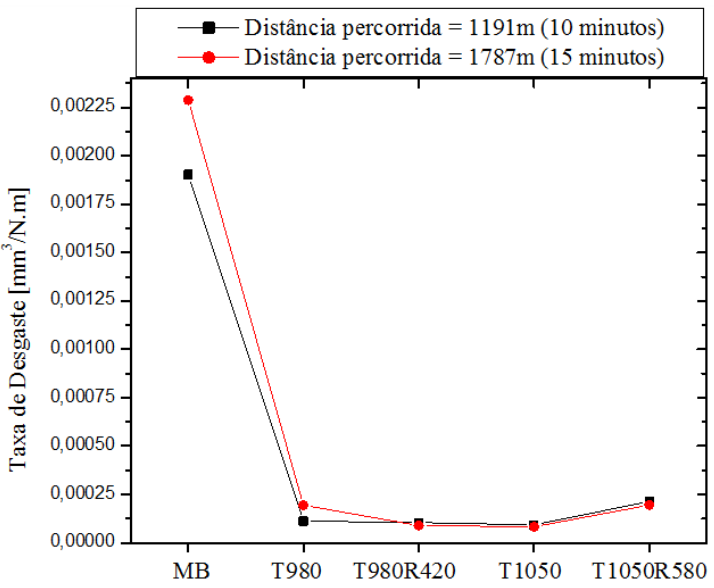

Figura 10: Taxa de Desgaste em função da dureza dos materiais estudados.

A Figura 11 apresenta resistência ao desgaste do material estudado, nas várias condições de tratamento térmico. Observa-se que os materiais de maior dureza apresentam maior resistência ao desgaste.

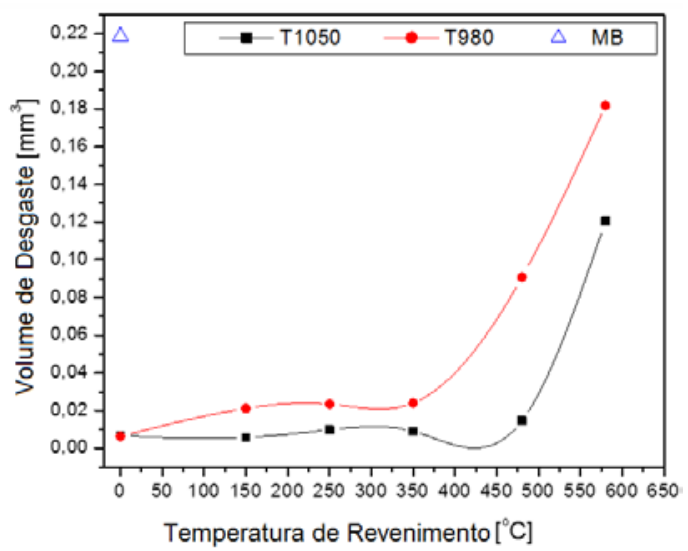

Figura 11: Gráfico do Volume de Desgaste em função da Temperatura de revenimento para o material base (MB), material temperado após austenitização a $980^{\circ} \mathrm{C}$ (T980) e material temperado após austenitização a $1050^{\circ} \mathrm{C}(\mathrm{T} 1050)$. 
Observa-se um ligeiro aumento da resistência ao desgaste, caracterizado pelo menor volume de desgaste apresentado pelo material com o aumento da temperatura de revenimento até uma temperatura de aproximadamente $450^{\circ} \mathrm{C}$ devido ao endurecimento secundário, com posterior aumento no volume desgastado devido ao amolecimento do material. O material T1050 apresenta maior resistência ao desgaste comparado ao MB e T980, independente da temperatura de revenimento realizado, com exceção dos materiais T980 e T1050 somente temperados. Assim, a resistência ao desgaste deste material está diretamente relacionado com a dureza, influenciado pelo efeito do tratamento térmico na microestrutura do material.

Na Figura 12 são apresentadas as calotas representativas obtidas no ensaio de desgaste. Pode-se observar que as marcas produzidas são similares independente do tratamento e tempo de ensaio estudado. Verifica-se em todos os casos sulcos de desgaste característicos de ensaios abrasivos.

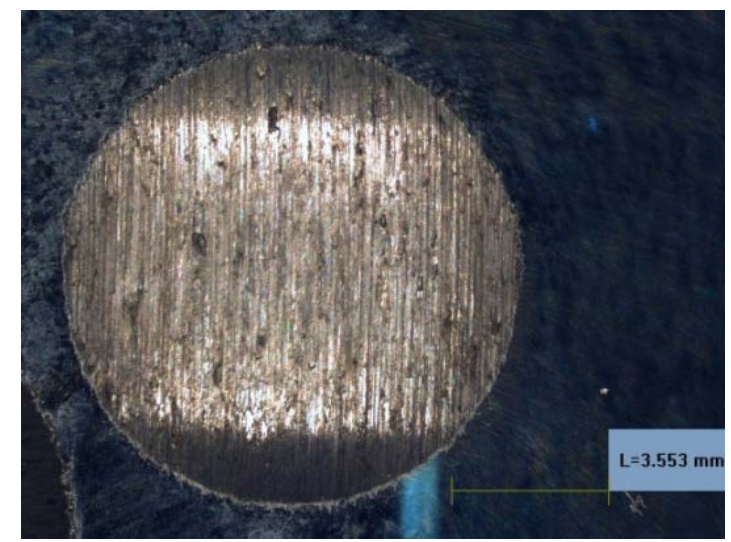

(a)

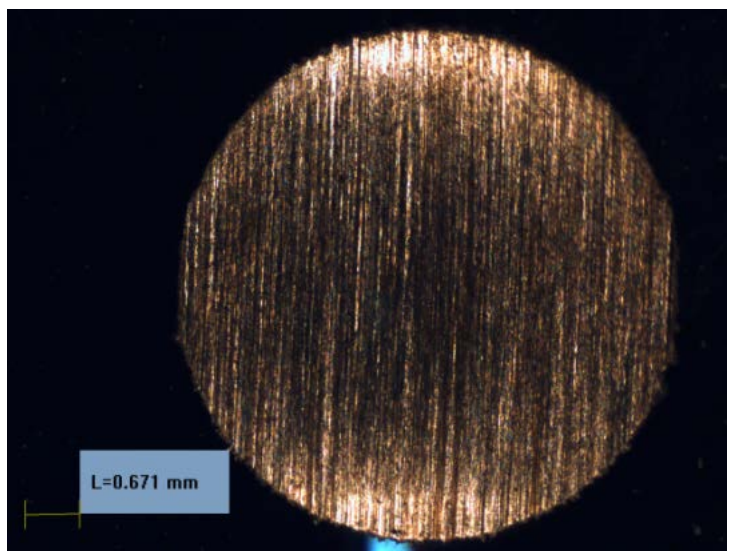

(c)

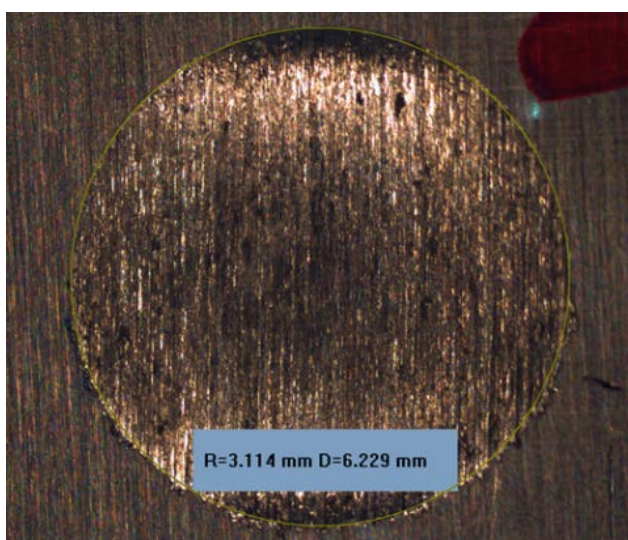

(b)

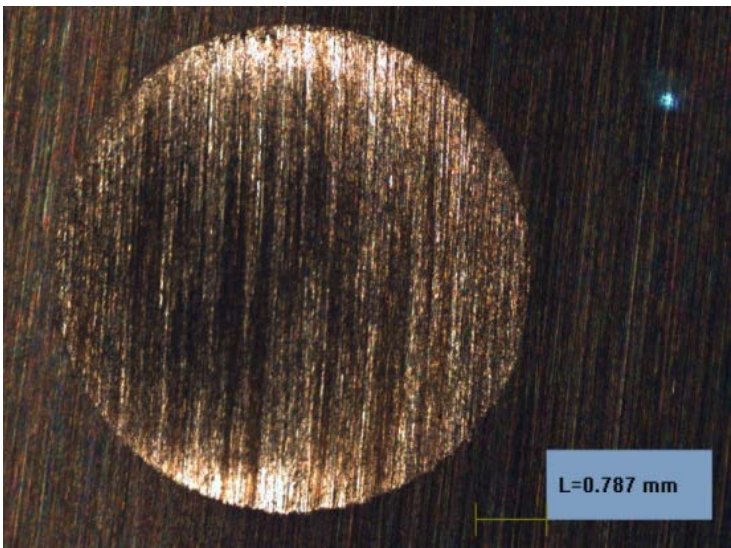

(d)

Figura 12: Calotas de desgaste obtidas nos ensaios de (a) MB a 10 minutos; (b) T1050R580 a 10 minutos, (c) T980 a 15 minutos e (d) T980R420 a 15 minutos

O tipo de mecanismo de abrasão tem um efeito significativo na taxa de desgaste do tribosistema. Os mecanismos de abrasão dependem da natureza do movimento das partículas abrasivas na região de contato entre a esfera e a amostra. A abrasão a 3-corpos, denominada abrasão por rolamento, acontece quando as partículas abrasivas não ficam presas à superfície da esfera, mas rolam na região de contato (rolling wear) produzindo uma superfície altamente deformada por múltiplas micro-penetrações, sem direção preferencial evidente, sendo dominante em condições de baixas forças aplicadas e altas concentrações de partículas abrasivas. Já a abrasão a 2-corpos, denominada abrasão por deslizamento ou riscamento, acontece quando a partícula abrasiva se prende à esfera e atuam como micro-corte e sulcam ou arrancam micro-cavacos da região de contato (grooving wear), produzindo uma série de riscos paralelos na superfície, sendo dominante para condições de altas forças aplicadas e/ou suspensão abrasiva de baixa concentração [르, 28, 29, $\underline{30}$ ]. De acordo com BOZE et al. [27] para utilizar o teste de microabrasão para avaliar a resistência ao desgaste de um sistema seria essencial assegurar a ocorrência de um único mecanismo de abrasão, no entanto os dois mecanismos podem ocorrer simultaneamente, produzindo o modo de desgaste misto. 
Pode-se verificar que neste trabalho a tipo de desgaste abrasivo verificado é predominantemente por micro-riscamento.

\section{CONCLUSÕES}

O dispositivo desenvolvido neste projeto representou uma possibilidade prática e versátil de estudo do comportamento de materiais com tratamento térmico, quando submetidos ao desgaste microabrasivo. O equipamento apresentou resultados satisfatórios e reprodutibilidade com confiabilidade, visto o comportamento do desgaste no material de teste. O equipamento, de baixo custo, se mostrou bastante simples para sua utilização. Espera-se que, com a própria continuidade das pesquisas envolvendo o equipamento em questão, melhorias que se achar necessária pelo usuário sejam incrementadas no mesmo.

O tratamento de têmpera e revenimento é de fundamental importância para o aço inoxidável AISI 420, pois ele é fornecido no estado recozido (carbonetos com a morfologia em forma de glóbulos) em uma matriz ferrítica, ou seja, apresentando baixa dureza e resistência a corrosão. No entanto, ao ser tratado termicamente nas faixas de temperatura adequadas, adquire uma boa resistência à corrosão, alta dureza, resistência ao desgaste e dependendo da temperatura de revenimento, uma tenacidade satisfatória. Isto pode ser evidenciado pela maior dureza obtida pelo material austenitizado a $1050^{\circ} \mathrm{C}$ após tempera quando comparado ao tratamento de austenitização de $980^{\circ} \mathrm{C}$, independente da temperatura de revenimento.

Observa-se que o aço inox ABNT/AISI 420 tratado termicamente teve sua resistência ao desgaste aumentanda em aproximadamente $90 \%$ comparado ao material base. Isto se deve ao aumento da dureza alcançada pela microestrutura martensítica e carbonetos produzidos. Porém, a quantidade e tipo de carbonetos produzidos influenciam na resistência ao desgaste do material estudado. $\mathrm{O}$ aço revenido a $420^{\circ} \mathrm{C}$ obteve maior resistência ao desgaste devido ao endurecimento secundário, apresentando volume desgastado de 2,09 $\mathrm{mm}^{3}$ para um tempo de ensaio de 10 minutos e $2,66 \mathrm{~mm}^{3}$ para um tempo de ensaio de 15 minutos. Já o revenimento realizado a $580^{\circ} \mathrm{C}$ apresentou menor resistência ao desgaste dentre os materiais tratados, devido ao amolescimento favorecido pelo tipo e coalescimento dos carbonetso produzidos, apresentando volume de desgaste de $4,26 \mathrm{~mm}^{3}$ para 10 minutos de ensaio e $5,82 \mathrm{~mm}^{3}$ para 15 minutos de ensaio.

Pode-se observar um aumento na dureza do material com o aumento na temperatura de revenimento, que causa um aumento na resistência o desgaste até uma temperatura aproximada de $450^{\circ} \mathrm{C}$ decido ao endurecimento secundário, o qual diminui com o aumento da temperatura de revenimento devido ao amolecimento do material.

O aumento na distância de deslizamento aumentou sutilmente o volume de desgaste, com ligeiro aumento da taxa de desgaste microabrasivo. O tipo de desgaste predominante foi abrasivo por microriscamento, influenciado principalemnte devido a carga e abrasivo utilizado.

\section{AGRADECIMENTOS}

Á PPE FIOS pela fabricação do dispositivo.

\section{BIBLIOGRAFIA}

[1] HUTCHINGS, I. M. Tribology, friction and wear of engineering materials, Cambridge, Butterworth Heinemann, 1992.

[2] Norma DIN 50320: Análise sistemática dos processos de desgaste. Classificação dos fenômenos de desgaste, Metalurgia e Materiais. v. 53, pp. 619-622. 1997.

[3] GAHR, K.H. “Microstructure and wear of materials”, v. 10, New York, Elsevier, 1987.

[4] YAMAGUCHI, Y. “Tribology of plastic materials”, v.16, New York, Elsevier, 1990.

[5] SUH, N. P. “The delamination theory of wear”, Wear, v. 25, pp. 111-124, 1973.

[6] HARSHA, A.T., TEWARI, U.S. “Two-Body and Three-Body Abrasive Behavior of Polyaryletherketone Composites”, Polymer Testing, v. 22, pp. 403-418, 2003.

[7] WRIGHT, T.M., GOODMAN, S.B. "Implant Wear in Total Joint Replacement”, American Academy of Orthopaedic Surgeons, p. 176-185, 2001.

[8] STACHOWIAK, G.B., STACHOWIAK, G.W., CELLIERS, O. "Ball-cratering abrasion tests of high-Cr white cast irons”, Tribology International, v. 38, pp. 1076-1087, 2005. 
[9] STACHOWIAK, G.B., STACHOWIAK, G. W. "Wear mechanisms in ball-cratering tests with large abrasive particles”, Wear, v. 256, pp. 600-607, 2004.

[10] SILVA JUNIOR, W. M. Efeito da pressão de compactação e tamanho do pó de ferro na abrasão do ferro sinterizado oxidado a vapor, Dissertação de M. Sc., Universidade Federal de Uberlândia, Uberlândia, MG, Brasil, 2003.

[11] COZZA, R. C. Estudo do comportamento do coeficiente de desgaste e dos modos de desgaste abrasivo em ensaios de desgaste micro abrasivo. Dissertação de M. Sc., Escola Politécnica da Universidade de São Paulo, São Paulo, SP, Brasil, 2006.

[12] LOZZER, M. A., SCANDIAN, C., MACEDO, C. S. M., et al. "Microabrasão de compósitos de matriz metálica a base de tungstênio empregados em coroas de perfuração utilizadas em sondagem mineral”, In: 8 Congresso Iberoamericano de Engenharia Mecânica, Cusco, 2007.

[13] MELLO, J. D. B., BÁLSAMO, P. S. S. “Caracterização tribológica de aços para cutelaria: uma nova metodologia para determinar a resistência à perda de corte”, Tecnologia em Metalurgia e Materiais, v. 2, n. 4, pp. 25-29, 2006.

[14] CASTELETTI, L. C., FERNANDES, F. A. P., LOMBARDI NETO, A., et al., “Caracterização de camadas nitrocementadas por plasma produzidas no aço inoxidável austenítico AISI 316L”, Revista Escola de Minas, v. 63, n. 1, pp. 179-184, 2010.

[15] COZZA, R. C., RECCO, A. A. C., TSCHIPTSCHIN, A. P., et al. "Análise comportamental dos coeficientes de atrito e desgaste de sistemas revestidos a desgaste micro-abrasivo”, Tecnol. Metal. Mater. Miner., v. 6, n. 4, pp. 237-244, 2010.

[16] COSTA, A. D. Estudo do comportamento mecânico in vitro de dois compósitos restauradores odontológicos contendo nanopartículas. Dissertação de M. Sc., Universidade Federal do Rio de Janeiro, Rio de Janeiro, RJ, Brasil, 2007.

[17] GEE, M. G., GANT, A., HUTCHINGS, I., et al., "Progress towards standardization of ball cratering”, Wear, v. 255, pp. 1-13, 2003.

[18] RUTHERFORD, K. L., HUTCHINGS, I. M. “A micro-abrasive wear test with particular application to coated systems”, Surface and Coatings Technology, v. 79, pp. 231-239, 1996.

[19] ASTM. Designation ASTM A276-13: standard specification for stainless steel bars and shape, USA: ASTM International, 2013.

[20] A Designers' Handbook Series No 9002. Welding of stainless steels and other joining methods, USA: Nickel Development Institute, 1988.

[21] COSTA E SILVA, A. L. V., MEI, P. R. “Aços e ligas especiais”, 3 ed., São Paulo, Blucher, 2010.

[22] ABNT. “ABNT/NBR 6214: aço inoxidável: tratamento térmico”, Rio de Janeiro, ABNT, 1980.

[23] CHIAVERINI, V. “Aços e ferros fundidos”, 7 ed., São Paulo, ABM, 2008.

[24] PINEDO, C. E. “Tratamento térmico e superficial do aço inoxidável martensítico AISI 420 destinado a moldes para injeção de polímeros parte I: tratamento térmico”, In: 2o Encontro da Cadeia de Ferramentas, Moldes e Matrizes - ABM, pp. 281-292, São Paulo, 21 a 23 de Setembro, 2004.

[25] ISFAHANY, A. N., SAGHAFIAN, H., BORHANI, G. "The effect of heat treatment on mechanical properties and corrosion behavior of AISI420 martensitic stainless steel”, Journal of Alloys and Compounds, v. 509, pp. 3931-3936, 2011.

[26] PRABHUDEV, K. H. "Handbook of heat treatment of steels”, New Delhi, Tata McGraw-Hill, 1988.

[27] BOSE, K.., WOOD, R. J. K. “Optimum tests conditions for attaining uniform rolling abrasion in ball cratering tests on hard coatings”, Wear, v. 258, pp. 322-332, 2005.

[28] COZZA, R. C., MELLO, J. D. B., TANAKA, D. K., et al., "Relationship between test severity and wear mode transition in micro-abrasive wear tests”, Wear, v. 263, p.111-116, 2007.

[29] TREZONA, R. I., ALLSOPP, D. N., HUTCHINGS, I. M. "Transitions between two-body and threebody abrasive wear: influence of test conditions in the microscale abrasive wear test”, Wear, v. 225-229, pp. 205-214, 1999.

[30] ADACHI, K., HUTCHINGS, I. M. "Wear-mode mapping for the micro-scale abrasion test”, Wear, v. 255, pp. 23-29, 2003. 